\title{
Microwave-assisted synthesis of silver nanoparticles using benzo-18-crown-6 as reducing and stabilizing agent
}

\author{
Jolly Pal • Manas Kanti Deb • \\ Dhananjay Kumar Deshmukh
}

Received: 28 March 2013/Accepted: 29 April 2013/Published online: 10 May 2013

(c) The Author(s) 2013. This article is published with open access at Springerlink.com

\begin{abstract}
Benzo-18-crown-6 is employed to work as both reducing and stabilizing reagent in the reaction for synthesis of silver nanoparticles. Silver nanoparticles are analyzed using transmission electron microscope and UV-visible spectroscopic technique. The silver nanoparticles prepared in this way are uniform and stable, which can be stored at refrigerator for 5 months. Appearance of surface plasmon band at $420 \mathrm{~nm}$ indicated the formation of silver nanoparticles. Highly monodispersed stable silver nanoparticles were obtained within $3 \mathrm{~min}$ of microwave irradiation. Through transmission electron microscopy, silver nanoparticles were observed to be spherical.
\end{abstract}

Keywords Silver nanoparticles · Benzo-18-crown-6 ·

Microwave

\section{Introduction}

In the last few years, there have been considerable efforts dedicated to the preparation, characterization and applications of metal nanoparticles (NPs) (Pal and Deb 2012a, b, c, d, e; Pal et al. 2012, 2013; Pal et al. 2009; Shah et al. 2010; Bahgat et al. 2012; Kannan et al. 2012; Karuppuchamy et al. 2012; Nafees et al. 2012). Metal NPs are usually prepared by reduction of metal ions in solution. Meanwhile, because of the trouble-some aggregation of NPs induced by their high surface energy, surface passivating reagent and

J. Pal · M. K. Deb ( $\varangle)$ · D. K. Deshmukh

School of Studies in Chemistry, Pandit Ravishankar Shukla

University, Raipur 492 010, Chhattisgarh, India

e-mail: debmanas@yahoo.com

D. K. Deshmukh

e-mail: dhananjaychem@yahoo.in capping reagent are usually involved in the reaction system (Manna et al. 2001; He et al. 2001). The choice of the capping agent is very critical because it determines the stability, solubility, reactivity and even the size and shape of the NPs during the synthesis. Crown ether is a macrocyclic polyether whose structure contains hydrogen, carbon and oxygen atoms. Each oxygen atoms are confined between two carbon atoms and exhibits a conformation with a hole. The common names of crown ethers have a prefix to designate the total number of atoms in the cycle and a suffix to designate the number of oxygen atoms in the cycle. Compared with general heating treatment, microwave synthesis is in favour of homogeneous heating and easy nucleation of noble metal NPs (Thiebaut et al. 1993; Correa et al. 1998; Patel et al. 2005). So, here microwave is employed to synthesize silver nanoparticles (AgNPs). Noble metal nanomaterials have attracted attention because of their potential applications in catalysis, energy, electronics and biotechnology (Xu et al. 2004; Jiangmei et al. 2009).

In our experiment, we find that benzo-18-crown- 6 can work as both reducing and stabilizing reagent in the synthesis of AgNPs. Further, no other reagent is needed in the reaction except $\mathrm{AgNO}_{3}$. The particles were characterized by transmission electron microscopic (TEM) and UV-visible spectroscopy studies.

\section{Experimental section}

Materials

$\mathrm{AgNO}_{3}$ (Merck) and benzo-18-crown-6 (Fluka) employed were of analytical grade. They were used without further purification. All the aqueous solutions were prepared using triple distilled water. 


\section{Apparatus}

Glasswares were cleaned with ultrasonic cleaning bath, Spectra Lab India, model UCB-40 using mild detergent and after proper washing rinsed with ultrapure water. Cleaning normally lasts between 3 and $6 \mathrm{~min}$. Ultrasonic cleaning uses cavitation bubbles induced by high frequency pressure (sound) waves (usually from 20 to $400 \mathrm{kHz}$ ) to agitate a liquid. The agitation produces high forces on contaminants adhering to substrates like metals, plastics, glass, rubber and ceramics. This action also penetrates blind holes, cracks and recesses. A Samsung CE2877 domestic microwave oven $(850 \mathrm{~W})$, Samsung India Electronics Ltd. New Delhi, India was employed for irradiating solutions. Absorption spectra were recorded in a Varian Carry 50 UV-visible spectrophotometer equipped with a peltier temperature controller unit. The particle size and morphology of the NPs were characterized by Morgagni 268D TEM operating at $80 \mathrm{~KB}$ (Mega view III Camera CCD) at the All India Institute of Medical Sciences (AIIMS), New Delhi.

\section{Preparation of AgNPs}

In a typical procedure, $1 \mathrm{ml}$ of $0.2 \mathrm{M}$ benzo-18-crown-6 and $10 \mathrm{ml}$ of $0.0001 \mathrm{M} \mathrm{AgNO}_{3}$ were taken in a $50-\mathrm{ml}$ conical flask and placed in a microwave oven that was operated at the $300 \mathrm{~W}$ for $3 \mathrm{~min}$. The colourless solution instantaneously turned into the characteristic pale yellow colour, indicating the formation of AgNPs.

\section{Results and discussion}

Formation of AgNPs

The advantage of microwave-mediated synthesis over the conventional heating is the improved kinetics of the reaction generally by one or two orders of magnitude, due to rapid initial heating and the generation of localized hightemperature zones at reaction sites (Liu et al. 2005). The TEM image of the AgNPs is shown in Fig. 1. The AgNPs, which were obtained in benzo-18-crown-6 under microwave irradiation after $3 \mathrm{~min}$ are nearly uniform and spherical in shape and well dispersed. It is interesting to find that AgNPs can be synthesized with benzo-18-crown-6 and $\mathrm{AgNO}_{3}$ promoted by microwave. Figure 2 shows the corresponding particle size distribution histogram of the AgNPs. The size distribution histogram reveals that such AgNPs range from 6 to $11 \mathrm{~nm}$ in size. About $25 \%$ of these NPs consist of particles with $6 \mathrm{~nm}$ diameter, $15 \%$ particles were of $7 \mathrm{~nm}$ size, $25 \%$ particles were of $8 \mathrm{~nm}$ size and size of the remaining particles was in the range of

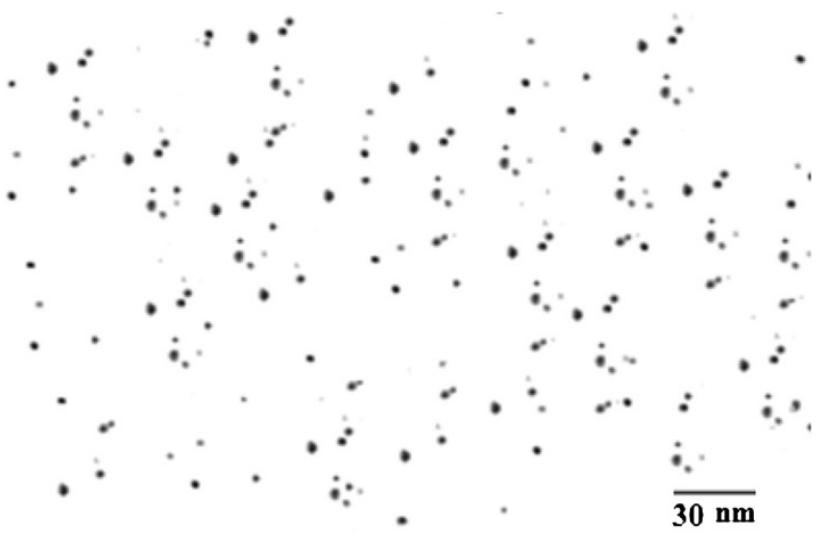

Fig. 1 TEM image of AgNPs

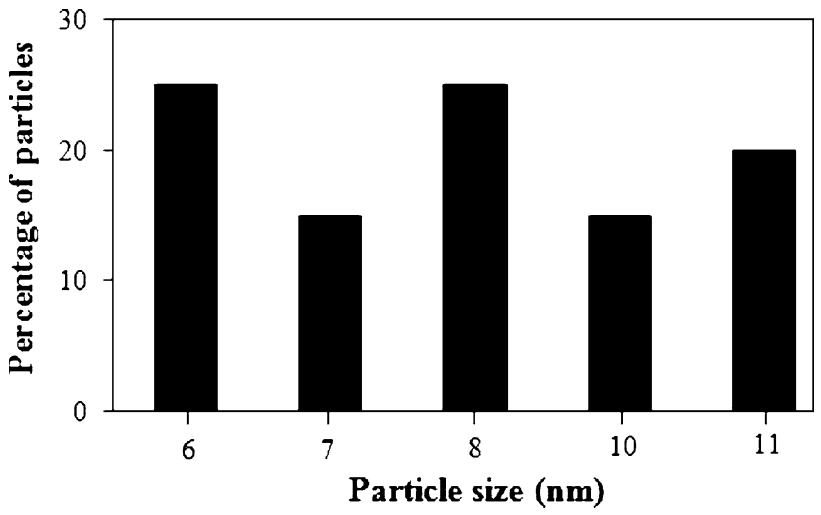

Fig. 2 Size distribution of the AgNPs synthesized under optimum experimental conditions

10-11 nm diameter. Figure 3 shows the typical UV-visible spectra of the silver colloidal solution. It can be observed that stronger absorbance peak appears at about $420 \mathrm{~nm}$. The peak is symmetrical and there is no obvious absorption range of $450-700 \mathrm{~nm}$, which indicates that negligible aggregation occurs in this reactive system and the NPs are well dispersed.

\section{Effect of microwave irradiation time and power}

The position and shape of plasmon absorption of noble metal nanoclusters are strongly dependent on particle size, dielectric medium and surface-adsorbed species (Kamat et al. 1998; Heilmann et al. 1999). The formation process and the optical properties of the AgNPs can also be identified from both the colour change and UV-visible spectra of the solutions. The UV-visible absorption spectra of the aqueous solutions containing prepared AgNPs are shown in Figs. 4 and 5. The changes of shape of the absorption spectra were obvious during the whole reaction process. As shown, the heating time ranges taken were 3, 6, 9, 12 min. (Table 1) and the power ranges taken were 180, 300, 


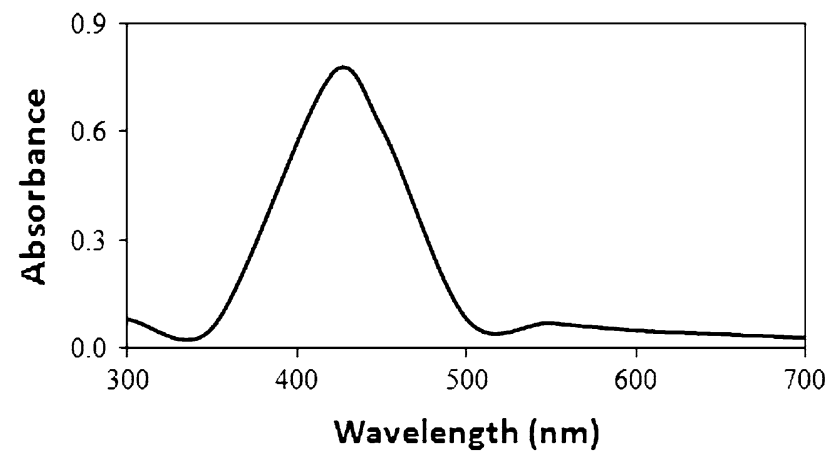

Fig. 3 UV-visible spectra of AgNPs

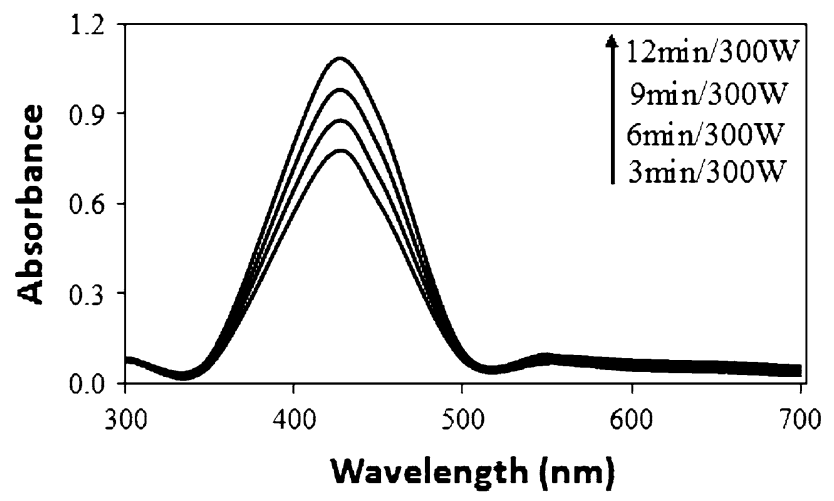

Fig. 4 UV-visible spectra of AgNPs at different heating time under microwave irradiation

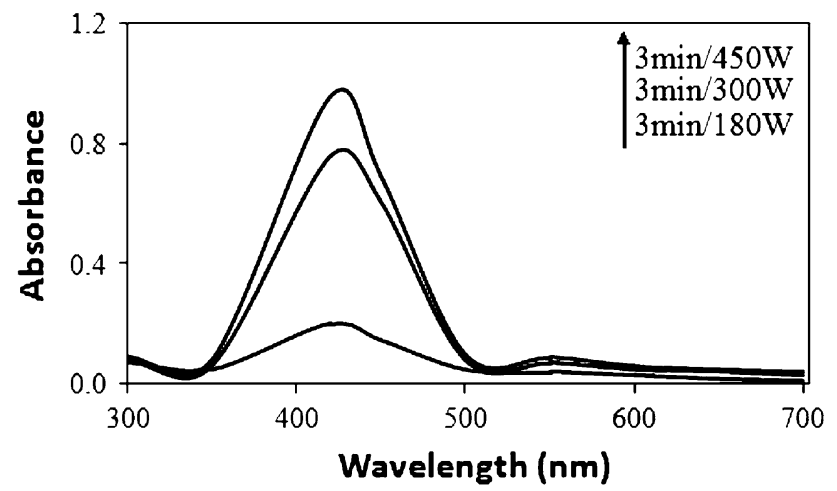

Fig. 5 UV-visible spectra of AgNPs at different heating power under microwave irradiation

$450 \mathrm{~W}$ (Table 2). The solution was observed to change from colourless to transparent yellow to dark yellow indicating the formation of larger number of NPs with increased heating time. There is only one symmetric absorption peak at $420 \mathrm{~nm}$ which is the characteristic surface plasmon resonance of spherical AgNPs (He et al. 2001). According to Mie's theory, small spherical nanocrystals should exhibit a single surface plasmon band, whereas anisotropic particles should exhibit two or three bands, depending on their shape. Similarly, the gradual increase in heating power also produces the same effect due to the reasons mentioned as above.

\section{Stabilization of AgNPs}

As shown in Fig. 6, the absorbance spectra of silver colloidal solution have been only slightly changed in position and absorbance intensity, but exhibit invariability in shape and symmetry, after the solution has been stored for 5 months at refrigerator $\left(-4{ }^{\circ} \mathrm{C}\right)$ and the solution is still clear yellow with no obvious change of colour. The result

Table 1 Effect of microwave irradiation time at constant power on the formation of AgNPs

\begin{tabular}{|c|c|c|c|}
\hline $\begin{array}{l}\text { S. } \\
\text { No. }\end{array}$ & Solution composition & $\begin{array}{l}\text { Irradiation } \\
\text { time/W }\end{array}$ & $\begin{array}{l}\text { Optical property of } \\
\text { resulting solutions }\end{array}$ \\
\hline 1 & $\begin{array}{l}0.0001 \mathrm{M} \mathrm{AgNO}_{3}+0.2 \mathrm{M} \\
\text { benzo-18-crown-6 }\end{array}$ & $3 \mathrm{~min} / 300 \mathrm{~W}$ & Pale yellow \\
\hline 2 & $\begin{array}{l}0.0001 \mathrm{M} \mathrm{AgNO}_{3}+0.2 \mathrm{M} \\
\text { benzo-18-crown-6 }\end{array}$ & $6 \mathrm{~min} / 300 \mathrm{~W}$ & $\begin{array}{l}\text { Comparatively } \\
\text { dark yellow }\end{array}$ \\
\hline 3 & $\begin{array}{l}0.0001 \mathrm{M} \mathrm{AgNO}_{3}+0.2 \mathrm{M} \\
\text { benzo-18-crown- } 6\end{array}$ & $9 \mathrm{~min} / 300 \mathrm{~W}$ & $\begin{array}{l}\text { Comparatively } \\
\text { dark yellow }\end{array}$ \\
\hline 4 & $\begin{array}{l}0.0001 \mathrm{M} \mathrm{AgNO}_{3}+0.2 \mathrm{M} \\
\text { benzo-18-crown- } 6\end{array}$ & $12 \mathrm{~min} / 300 \mathrm{~W}$ & $\begin{array}{l}\text { Comparatively } \\
\text { dark yellow }\end{array}$ \\
\hline
\end{tabular}

Table 2 Effect of microwave irradiation power at constant time on the formation of AgNPs

\begin{tabular}{llll}
\hline $\begin{array}{l}\text { S. } \\
\text { No. }\end{array}$ & $\begin{array}{l}\text { Solution } \\
\text { composition }\end{array}$ & $\begin{array}{l}\text { Irradiation } \\
\text { time/W }\end{array}$ & $\begin{array}{l}\text { Optical property of } \\
\text { resulting solutions }\end{array}$ \\
\hline 1 & $\begin{array}{c}0.0001 \mathrm{M} \mathrm{AgNO}_{3}+0.2 \mathrm{M} \\
\text { benzo-18-crown-6 }\end{array}$ & $3 \mathrm{~min} / 180 \mathrm{~W}$ & Very light yellow \\
2 & $\begin{array}{c}0.0001 \mathrm{M} \mathrm{AgNO}_{3}+0.2 \mathrm{M} \\
\text { benzo-18-crown-6 }\end{array}$ & $3 \mathrm{~min} / 300 \mathrm{~W}$ & Pale yellow \\
3 & $\begin{array}{c}0.0001 \mathrm{M} \mathrm{AgNO}_{3}+0.2 \mathrm{M} \\
\text { benzo-18-crown-6 }\end{array}$ & $3 \mathrm{~min} / 450 \mathrm{~W}$ & $\begin{array}{c}\text { Comparatively } \\
\text { dark yellow }\end{array}$ \\
\hline
\end{tabular}

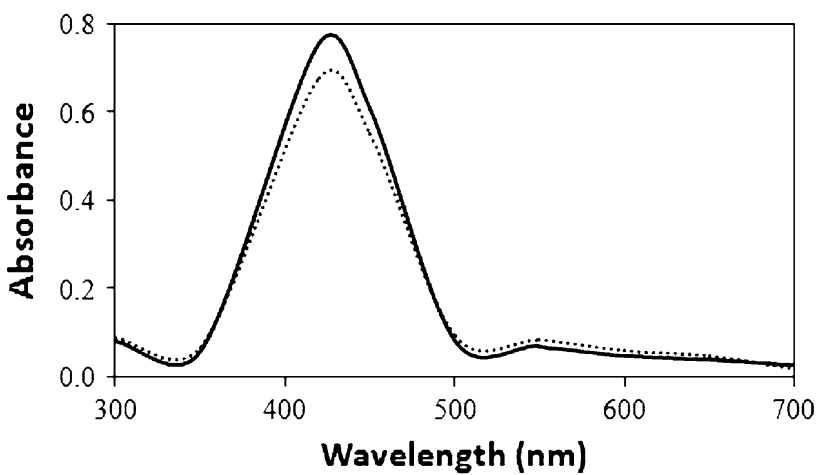

Fig. 6 UV-visible spectra of AgNPs after it is stored for 5 months at refrigerator 
implies that the AgNPs prepared by this method are very stable with negligible aggregation.

\section{Conclusions}

AgNPs were synthesized under microwave irradiation using benzo-18-crown-6 as both reducing and stabilizing reagent. Not only the heating is faster through microwave radiation, but also the temperature distribution of the solution is more uniform. As such, this has led to the fast reaction rate and narrow size distribution of the AgNPs in the current study. Silver colloidal solution was characterized by UV-visible spectroscopy. The UV-visible spectra showed that these synthesised samples have absorbance peak at $420 \mathrm{~nm}$. The AgNPs prepared in this way are uniform and stable, and can be stored at refrigerator for 5 months without any visible change.

Acknowledgments The authors are thankful to the Head, School of Studies in Chemistry, Pt. Ravishankar Shukla University, Raipur, India for providing laboratory facilities. Authors are also thankful to Department of Anatomy, All India Institute of Medical Sciences (AIIMS), New Delhi for providing TEM photographs.

Open Access This article is distributed under the terms of the Creative Commons Attribution License which permits any use, distribution, and reproduction in any medium, provided the original author(s) and the source are credited.

\section{References}

Bahgat M, Farghali A, Rouby W, Khedr M, Ahmed M (2012) Adsorption of methyl green dye onto multi-walled carbon nanotubes decorated with $\mathrm{Ni}$ nanoferrite. Appl Nanosci. doi: 10.1007/s13204-012-0127-3

Correa R, Gonzalez G, Dougar V (1998) Emulsion polymerization in a microwave reactor. Polymer 39:1471-1474

He ST, Yao JN, Jiang P, Shi DX, Zhang H, Xie S, Pang S, Gao H (2001) Formation of silver nanoparticles and self assembled twodimensional ordered superlattice. Langmuir 17:1571-1575

Heilmann A, Kresow A, Gruner M, Kreibig U (1999) Optical and electrical properties of embedded silver nanoparticles at low temperatures. Thin Solid Films 343:1751-1778

Jiangmei Y, Huiwang T, Muling Z, Jun T, Shihong Z, Zhiying Y, Wei W, Jiaqiang W (2009) PVP-capped silver nanoparticles as catalyst for oxidative coupling of thiols to disulfides. Chin J Catal 30:856-858

Kamat PV, Flumiani M, Hartland GV (1998) Picosecond dynamics of silver nanoclusters photoejection of electrons and fragmentation. J Phys Chem B 102:3123-3128
Kannan R, Arumugam R, Ramya D, Manivannan K, Anantharaman P (2012) Green synthesis of silver nanoparticles using marine macroalga chaetomorpha linum. Appl Nanosci. doi:10.1007/ s13204-012-0125-5

Karuppuchamy S, Andou Y, Endo T (2012) Preparation of nanostructured $\mathrm{TiO}_{2}$ photoelectrode for flexible dye-sensitized solar cell applications. Appl Nanosci. doi:10.1007/s13204-012-0140-6

Liu FK, Wen HP, Cheng CY, Jung KC, Hsiang KF, Tieh C (2005) Formation of silver nanorods by microwave heating in the presence of gold seeds. J Cryst Growth 273:439-445

Manna A, Imae T, Iida M, Hisamatsu N (2001) Formation of silver nanoparticles from a $N$-hexadecylethylenediamine silver nitrate complex. Langmuir 17:6000-6004

Nafees M, Ali S, Idrees S, Rashid K, Shafique M (2012) A simple microwave assists aqueous route to synthesis $\mathrm{CuS}$ nanoparticles and further aggregation to spherical shape. Appl Nanosci. doi: 10.1007/s13204-012-0113-9

Pal J, Deb MK (2012a) Effective removal of brilliant green dye from aqueous solution by adsorption onto biopolymer supported silver nanoparticles beads. J Indian Chem Soc 89:1689-1695

Pal J, Deb MK (2012b) Efficient sorption of basic organic dyes from aqueous solution using green synthesized silver nanoparticles beads. J Dispers Sci Technol. doi:10.1080/01932691.2012. 739939

Pal J, Deb MK (2012c) Green formation and catalytic activity of palladium nanoparticles on brilliant green in aqueous solution. Indian J Environ Prot 32:574-578

Pal J, Deb MK (2012d) Microwave green synthesis of PVP stabilized gold nanoparticles and their adsorption behaviour for methyl orange. J Exp Nanosci. doi:10.1080/17458080.2012.667160

Pal J, Deb MK (2012e) Microwave synthesis of polymer coated silver nanoparticles by glucose as reducing agent. Indian J Chem Sec A 51:821-824

Pal A, Shah S, Devi S (2009) Microwave-assisted synthesis of silver nanoparticles using ethanol as a reducing agent. Mater Chem Phys 114:530-532

Pal J, Deb MK, Deshmukh DK, Sen BK (2012) Microwave-assisted synthesis of platinum nanoparticles and their catalytic degradation of methyl violet in aqueous solution. Appl Nanosci. doi: 10.1007/s13204-012-0170-0

Pal J, Deb MK, Deshmukh DK, Verma D (2013) Removal of methyl orange by activated carbon modified by silver nanoparticles. Appl Water Sci. doi: 10.1007/s13201-013-0087-0

Patel K, Kapoor S, Dave DP, Mukherjee T (2005) Synthesis of nanosized silver colloids by microwave dielectric heating. J Chem Sci 117:53-60

Shah S, Pal A, Gude R, Devi S (2010) Synthesis and characterization of thermo responsive copolymeric nanoparticles of poly (methyl methyacrylate-co- $N$-vinylcaprolactam. Eur Polym J 46(5):958967

Thiebaut JM, Roussy G, Medjram M, Garin F, Seyfried L, Maire G (1993) Durable changes of the catalytic properties of aluminasupported platinum induced by microwave irradiation. Catal Lett 21:133-138

$\mathrm{Xu}$ YP, Tian ZJ, Lin LW (2004) Nanostructure and catalytic performance of noble metal solid catalysts. Chin J Catal 25:331-338 